\title{
STUDY OF CUT-OVER OR BURNED LANDS
}

\author{
by W. M. Rober'Tson, Dominion Forest Service
}

\section{INTRODUCTION}

$\mathbb{T}^{\text {Hitat }}$ $\mathrm{HE}$ problem set our Committee is the preparation of a comprehensive plan, as simple as possible, for the study of the silvicultural conditions of cut-over lands, a plan acceptable to the members of our Committee, and that will be endorsed by the Canadian Society of Forest Engineers. If we are successful, the plan is to be made available to any organization undertaking surveys of this nature. The purpose in preparing such a plan is to ensure that all essential, but no unnecessary data are taken in future surveys but taken in a manner sufficiently standardized so that the results of one survey may be compared with those of another.

During the past twenty years many surveys of cut-over lands have been made, and probably no two of them have been conducted on the same plan. No doubt each plan has commendable faatures, but it is probably just as certain that some weakness has been discovered in each before the final report was issued.

If we can profit fully from the experience of those who have prepared previous plans and therefrom evolve a single plan incorporating the strong features and correcting those that are weak, we will have solved the problem set us.

It is often claimed that standardizing of methods constitutes unwarranted restriction of individual initiative. It is quite true that the investigator should not be needlessly restricted concerning the data he collects, or the deductions he can make therefrom. Experience has shown, however, that unless a definite general outline is provided, much waste effort results and often essential data are inadequately recorded or entirely omitted. Too much motion has tieen lost by such trial and error methods.

In confirmation of this view, quotation is taken from "Outlines for Permanent Sample Plot Investigation," 1936, published by the International Union of Forest Research Organizations.

"There must be agreement between the several workers as to the basic principles of the enquiry as well as some degree of uniformity in the methods to be used." "It must be emphasized that there is no intention to restrict in any way the freedom of the individual research institute beyond what is essential for purposes of comparability." "Comparability of results would also be made easier if a standard set of forms were used for recording the measurements and in working up the data."

After examining a number of plans and reports concerning so-called "regeneration surveys," it would seem that the objects of the surveys extend much further than the title implies, and rightly so. It is not sufficient to know whether 
ample regeneration of the species concerned is occurring. The seedlings must be followed through to saplings, poles and merchantable material. There is usually prolific regeneration of white pine under seed trees, but it is comparatively seldom that the regeneration survives more than a few years. Usually the problem is to study all the conditions and factors of cut-over or burned lands which concern future supply. Therefore, a more apppropriate title for these and allied surveys would be "Study of Cut-Over or Burned Lands."

A comprehensive study of the specific subject, regeneration, requires so much data related to other conditions of the stand that comparatively little additional material is necessary upon which to base a report on the general conditions of the lands. A study of regeneration requires information pertaining to history, site, character of cutting or burn, advance growth, and main stand. Little additional information is required to determine the growth rate, the future prospects, or even upon which to base a working plan. Usually the additional costs involved to make a complete survey will be justified. It would seem, therefore, that the task of this Sub-Committee is to prepare an outline as simple as possible for the study of cut-over or burned lands from all phases.

\section{OBJECT}

The object of such a survey is to record the forest conditions on potentially forest lands, in particular, lands where the forest cover has been disturbed by cutting, burning, or other abnormal depletion factor; to relate the conditions to the depletion factor. The conditions thus determined may provide the basis for more intensive investigation of fundamental factors involved.

The usual procedure followed is to divide and subdivide the field records until, if possible, the samples concerning a single factor are segregated and a complete report will require sufficient samples of each subdivision to provide a truly representative average. The general forest class should be divided into site and aspect classes, subdivided into types, degree and date of cut or degree and date of burn, degree and date of wind, fungus, or insect epidemic. For each subdivision samples of the main stand, saplings and reproduction are required. Records should be taken of timber cut, and of mortality. Growth data, either by stem analysis or increment borings, are necessary. Height measurements and, if form class volume tables are to be used, form class measurements are needed. Seedlings should be classified by height and age to determine whether they are advance growth or new reproduction, and whether thrifty or suppressed.

Almost invariably insufficient consideration has been given to one or more of these factors in previous surveys. A uniform classification and a standard outline would greatly increase the value of the work. 
Forest Class

\section{CLASSIFICATION}

The forest classification into zones and belts just completed by W.E. D. Halliday and which supersedes the work of Dr. B. E. Fernow is based on differences of climate, geological structure, and resultant variations in tree association. It is the most comprehensive classification yet prepared. Other classifications are local in scope and restricted by provincial boundaries. It would seem, therefore, that Halliday's classification, which has received general approval, should be accepted.

Site Class

Heretofore the importance of site in relation to silviculture and more particularly in relation to silvics has not been sufficiently recognized. Site is the growth quality of the soil, the net result of all the environment factors of soil, climate, topography, and plant and animal life. Site may be classified on the basis of age-height-growth. But a good deal of progress has been made with a classification on the basis of indicator species. Intensive research is necessary to determine the site classification for a given district, but once the classification and indicator species are determined, the sites are more readily recognized and designated, than by the age-height method. Therefore, the indicator species method should be adopted.

Types

There is divergence in the matter of type classification. The classification most generally used now seems to be that of the four types-hardwood type (75 per cent or more of stems, hardwood species); mixedwood type (less than 75 per cent, either softwood or hardwood): sof twood type ( 75 per cent or more of stems softwood). Swamp type-this classification might be accepted.

Sub-types

In many cases a type classification is not sufficiently fine. The study may be concerned with white pine or jack pine, yellow birch or white birth. The most common procedure seems to be to classify sub-types by the major trec species. The classification recognized by the Dominion Forest Service is as follows for eastern Canada:

\section{SOFTWOOD TYPE}

Sub-type 1. Pine (white or red pine predominating)

2. Jack pine

$\mathrm{PW}, \mathrm{Pr}$

3. Balsam-spruce

$\mathrm{Pj}$

B.S.

SWAMP TYPE

Sub-type 4. Black spruce

$\mathrm{Sb}$

5. Cedar-larch

C 


\section{HARDWOOD TYPE}

6. Intolerant hardwood (white birch

or poplar predominate),

BWA

7. Tolerant hardwood (yellow birch, maple, beech, etc.) ByM

MIXEDWOOD TYPE

Sub-type 8. Intolerant hardwoods-Pine

BWA-P

9. Intolerant hardwoods-Jack pine

$B w A-J$

10. Intolerant hardwoods-Balsam-spruce

BwA-B.S.

11. Tolerant hardwoods--Pine

ByM-P

12. Tolerant hardwoods-Balsam-spruce

ByM-B.S.

Degree and Date of Cut

It is important to know the relationship between the original and the remaining stand, the degree of opening that resulted, to make a satisfactory deduction of the effect of the cutting upon wind firmness, increment, reproduction and change in stand composition. This information can only be obtained by stump measurements. When more than one cut occured, the stumps of each date should be separated. It is, of course, desirable to separate the tally by species, but every stump diameter and age should be recorded, whether species can be positively identified or not .

The date of cut, not only the year, but the month, is valuable information, particularly for recent cuts. There may be definite relationship between season of cutting and the subsequent reproduction conditions.

A classification for degree of cutting in spruce-balsam stands used some years ago was:

10 trees or less per acre-light cutting

10 to 20 trees per acre-moderate cutting

Over 20 trees per acre-heavy cutting.

Lacking a better classification, this one might be continued for pulpwood studies.

Degree and Date of Fires

There does not seem to be a suitable classification for the degree or intensity of fires, although it is very important information. It is essential too to know whether the area has been repeatedly burned. The season of the year at which the fire occurred may also have an important bearing on the conditions of reproduction that follow. The whole problem of manner of recording burned area data is one for standardization.

\section{Degree and Date of $W$ indfall}

Wind damage should be related in as much detail as possible to the logging operations, and to meteorological records. A schedule of intensity of windfall should be devised. Season of the year is important in relation to reproduction. 
Notes on rate of decay- and general effect of suppression or otherwise upon seedling germination and growth are desirable.

Insect and Fungus Damage

This phase of the work should be planned with the co-operation of the entomological and pathological divisions of the Department of Agriculture.

Samples

The question of samples is so dependent upon the method of survey that the discussion of them will be given later.

\section{METHOD OF SURVEY}

Surveys of this class may be either single examination, semi-permanent, or permanent in nature.

The single examination method provides for a statement of conditions as they exist at the time, and for an estimate of the growth and mortality during the recent past. The method is the least expensive, and provides the information at once; but the information is less reliable than that obtained by either of the other methods.

The basis of the semi-permanent method is that the same area be resurveyed periodically at five or ten-year intervals, and the difference between the stands represents the net development during the elapsed interval. This method requires that the strips or line-plots under observation be sufficiently marked at the time of the first survey that they can be located and identified at the time of measurement. In addition to the information obtainable by the single examination method, this method provides for a statement of the net development during the interval. However, the usual procedure in the past did not provide for a statement of the mortality during the interval. This weakness can be overcome by marking the dead trees at time of establishment and at each subsequent examination.

The permanent sample plot method provides the most complete information, but on account of comparatively high costs entailed, its use is very restricted. As each tree on a permanent sample plot is described in detail and remeasured at intervals of five or ten years, complete information on net and gross development of the stand is supplied. Studies of the reproduction are usually confined to small sub-plots of the permanent sample plot.

The most suitable system is a combination of the semi-permanent survey and permanent sample plot methods. The former method provides a general and extensive sampling of the area, and by means of it the location representing average conditions can be found for a few permanent sample plots.

It would seem, therefore, that two outlines will be required, the one or single examination surveys, the other for semi-permanent and permanent or re-examination surveys. For the present, however, attention might be confined to the latter class. 
Purpose

To determine (1) the condition of the stand at the time of the first survey; (2) at the time of the second survey; (3) the net development of the stand in the interval between the surveys.

\section{Method of Survey}

The line-plot system offers several advantages over the strip. system. It lends itself more readily to statistical analysis. Plots may be carefully measured; and every tree within the plot may be tallied. The amount of material tallied is greatly reduced. The method is more rapid. The extra time required to delineate the plots is more than offset by the reduction in amount surveyed.

The interval between plots and between strips should be the same. What that area should be depends upon the area to be covered, and the regularity of conditions upon it. This can be calculated by statistical analysis after a few strips have been run. In actual practice, however, it will usually be determined by the area to be covered and the man-days available. A common practice is to establish a square chain plot at ten-chain intervals. This may vary from five chains in small or very irregular areas to twenty chains in large or very regular areas. If the area is so large that it cannot be covered by samples at twenty chain intervals, the conditions are likely to be so varied that it would be preferable to select blocks within the area and sample each block at not more than twenty chain intervals. Mechanical selection of plots should be rigidly adhered to except where they would thus fall in water or absolutely non-productive land, or when two distinct conditions of site or type occur within the plots. In the latter event, the plot location should be advanced or withdrawn a fraction of a chain so that only one site or type is represented in the sample.

Aerial maps are of great value in determining the general area to be covered, location of base lines, direction of strips, and waste areas that may be avoided. The areas of types, to which the ground survey data may be applied, can be more accurately determined by aerial maps than by any other means.

\section{General Forest Condition}

Interest is centred on cut-over conditions and not on areas where the main crown cover is complete or nearly so, therefore selection should be made with that object in view. Nevertheless, when the mechanically distributed plots fall on virgin stands or full crown cover conditions, they should be established. The data will be required for control or comparison.

Belt

A single survey should be confined to one forest belt, and the area should be as well within the boundaries of the helt as possible, thus to avoid marginal conditions. 
Line-the line should be blazed so that it can be readily located for remeasurement.

Plots

Each plot, one square chain (01 acre) in area should be accurately measured with chain and the boundaries should be marked with string or chain while the records are being taken. As the area is so small, a tree more or less will seriously affect the average.

Sub-plots for the record of reproduction and vegetation should be in the form of a transect of the plot, the dimensions should be $6.6^{\prime} \times 66^{\prime}$, a tenth of one square chain 0.01 acre in area. The corners of plots and subplots should be marked with pickets, one of them bearing the plot number.

Sites

At present there is no uniform site classification for Canada, but considerable progress is being made with the classification based on indicator species. There are many who prefer to base site on age-height. In the most of the surveys to date, however, the factor of site has been ignored. It seems likely that a relationship between the indicator species and the age-height classifications will be found and until a single standard is approved one or other of these two classes should be recognized for every survey. Indicator species classification takes into account soil, topography, aspect and soil cover. These factors should be related to the age-height method when it is used. The site should be determined for every plot. The indicator species should be recorded on the tally sheet before definitely designating and recording the site.

Types

The question of type classification to be adopted is subject for discussion. The four type classification - - wamp, softwood, mixedwood and hardwood, is probably the most simple. Some may think that both tolerant and intolerant hardwood types should be recognized, which would require subdivision of the mixedwood type as well. Others may contend that the pines should be separated from balsam-spruce, thus subdividing both softwood and mixedwood type. A solution might be to accept the four-type classes; and for special surveys recognize certain sub-types as well.

The type designation should be based on the stand on the sample plot and should not be influenced by the surrounding conditions.

Age-Class

Some division into age classes is essential but because of very unevenaged nature of cut-over lands in general, it is impracticable to segregate stands even into twenty-year classes. However, attempt should be made to recognize the following classes- $1-20$ years, 21-40 years, 41-60 years, 61-100 years, and 101 years and over. Where there is more than one age-class represented on the plot the age of the most important section should govern. In compiling 
growth data, however, the trees of each age-class should be separated, and the proper growth curve for each age-class applied.

Density

Four degrees of density should be recognized and indicated by numbers $12,3,4$. These densities are:

1. Sparse, up to 50 percent shaded at noon

2. Understocked, 51 to 80 per cent shaded

3. Fully stocked, 81 to 100 per cent shaded

4. Overstocked, where growth is being retarded by crowding.

Tally

Every living tree over 0.5 " D.B.H. on the plot should be tallied by oneinch diameter classes. In making the tally lumber crayon should be used to mark trees as tallied to ensure that every tree is tallied once and only once.

Tally should be taken of all dead standing or down trees that are estimated to have died during the past ten years.

Every dead standing tree should be blazed so that at the remeasurement they will not be included with those that die during the interval between surveys.

All stumps should be tallied by species and by date of cut if possible.

Height measurements should be taken on a few trees on each plot from which diameter-height curves for each species, site and type can be prepared.

Increment borings to show the growth for the past ten vears should be taken on a few mechanically selected trees on each plot to compute the gross periodic increment for each species, site and type.

Scedlings of all tree species up to and including 0.5" D.B.H. found on the subplot should he recorded, preferably classified by height, and age-classes.

Occurrence of indicator species found on the subplot should be recorded.

Records of the soil, its class, approximate depth, and moisture conditions should be taken.

\section{COMPILATION}

Data should be compiled daily so that omission or errors in field notes may be detected. Compiling can only be carried as far as posting the tally sheet records to the summary forms until the end of the season.

There is so much involved in methods of compilation and preparation of report that it should form the basis of separate study. However, since further field work depends upon some of the results of computation, some reference to the subject must be made here.

A separate stand table, the average of all the plots within the class is required for each site, type and age class. The stand table should show the number of stems and volumes for each species by diameter classes. The volume 
should be total cubic volume. Merchantable volume in cubic foot or board foot may also be shown if required.

Mortality and net and gross increment for the decade just past may also be shown on this table.

Regeneration, vegetation, soil data, and data pertaining to logging, fire and other history nuust also be summarized.

\section{PERMANENT SIMPLE PLOTS}

Purpose

To determine the development of each tree on the plot during the period under observation.

The Plot

At least one permanent sample plot of not less than one-acre, should be established on each important site-type.

Obviously to represent average conditions the stand selected should correspond closely to that of the average stand table. Therefore the average stand table should serve as a guide in selecting the location. The plot should not vary from the average in total number of stems and in total basal area by more than 10 per cent.

Although surveying and mapping of the plot may be done at any time, the measurements of diameter and height should not be done during the growing season, June and July.

For the sake of simplicity in establishment and recording, the shape of the plot should be square or rectangular. Boundaries should be marked by blazed or painted line, the corners by substantial posts. A protection border not less than fifty feet wide should surround the plot. Conditions in this border should be the same as those in the plot.

The Records

Detailed description of the plot should be recorded. These should include -forest description, type, site, density, aspect, altitude, topography, soil profile, ground cover, history, age, origin, fires, logging, slash, windfall, infestation.

Every tree over 0.5 " D.B.H. should be numbered. A map showing location of each numbered tree is desirable but not necessary. For tagging and mapping it is desirable to divide the plot into twenty-foot strips by use of string. The breast-height point ( 4.5 feet) should be marked. The tag nail is a good method. Diameters at breast height must then be measured, preferably with diameter tape. Heights should be measured for every tree on the plot if possible.

The most desirable form for sub-plots seems to be long and narrow. The long plot represents greater variations, the narrow plot lends itself to the count- 
ing of reproduction. The desirable size is $3.3^{\prime} \times 66^{\prime}$ ( 5 links by 100 links). Five such plots, .025 acre, the same area as four square rod plots.

In tallying the reproduction of these transect plots, each should be subdivided into ten $3.3^{\prime} \times 6.6^{\prime}$ ( 5 links $\times 10$ links) and the reproduction for each recorded separately. This division permits of relating conditions of reproduction found to influence factors such as burned patch, skidding trail, proximity of seed trees. It also permits of use of statistical analysis. Reproduction of all tree species should be recorded.

Good photographs are desirable and the location from which taken and the direction should be accurately recorded so that the same view may be obtained at remeasurement periods.

\section{Compilation}

As with the survey complete stand tables of main stand, saplings, and seedlings will be required.

\section{RESURVEY}

After an interval of five years more or less the survey lines should be re-run and plots remeasured. In determining the length of lapsed period, it must be remembered that a year's growth in diameter and height occurs largely in the months of June and July.

Effort should be made to relocate every plot originally established. But if any cannot be found, new plots should be made as close as possible to where the original plots were. Errors introduced thus will be insignificant and compensating in the average of a large number of plots.

Information required will be general description of changes in sanitary conditions and growth of seedlings, weed and vegetation. Remeasurement of diameters of living trees and those that have died in the interval. Heights of a few trees to check changes, if any, in diameter-height curves. Count of reproduction.

On the permanent sample plots all tagged trees must be remeasured for diameter and height. Trees that have entered the sapling class must be tagged, measured and added to the tally record. Reproduction must be counted.

\section{Compilation}

New stand tables must be prepared just as the first were made.

The stand tables must be compared; the difference between the first and second measurement represents the net increment.

The mortality should be computed and thereby the gross increment can be determined

Further work in connection with a complete outline is a description of suitable forms which should be standardized, and an outline for compilation methods. Before giving any consideration to these phases, however, the outline for field work should be analyzed. 